\title{
doispontos:
}

\section{Sartre versus Foucault: um embate sobre a teoria e a prática intelectual}

\author{
André Constantino Yazbek \\ Departamento de Filosofia, Universidade Federal Fluminense (UFF), Niterói, RJ, Brasil. \\ andre.yazbek@yahoo.com.br
}

Resumo: partindo do antagonismo representado pelas obras de Jean-Paul Sartre e Michel Foucault no horizonte da filosofia francesa contemporânea, este artigo procura divisar as linhas de força de alguns dos impasses e dilemas da teoria e da ação política no pensamento filosófico e o papel atribuído ao intelectual na contemporaneidade.

Palavras-Chave: Jean-Paul Sartre e Michel Foucault; ação intelectual; existencialismo; arqueologia e genealogia.

\section{Sartre versus Foucault: a confront between theory and intellectual practice}

Abstract: starting from the antagonism represented by the works of Jean-Paul Sartre and Michel Foucault in the context of contemporary French philosophy, this article aims to discern the impasses and dilemmas of theory and political action in the philosophical thought and the role of intellectuals in contemporary time.

Key-words: Jean-Paul Sartre and Michel Foucault; intellectual action; existentialism; arqueolology and genealogy.

I.

É bastante conhecido o debate que Michel Foucault tivera com Gilles Deleuze em 1972 acerca de um conjunto de questões que à época apontavam para um redimensionamento da própria relação entre a prática intelectual e o poder, vividos ainda sob o impacto da ambiência do Maio de 68 francês. Posteriormente publicado na revista L'Arc com o sugestivo título de "Os intelectuais e o poder", o diálogo travado entre ambos marca uma posição coincidente de recusa ao caráter universalista (e supostamente mistificador) da pratica filosófica e, no final das contas, da própria atividade política do intelectual na medida em que ele tende a alçar-se à posição de vanguarda dos embates públicos de sua época. Assim, ao passo que Deleuze afirmava a ocasião de uma nova maneira de vivenciar as "relações entre teoria e prática" - dando a elas um caráter fragmentário oposto à totalização pretendida pela teoria -, Foucault, de sua parte, rechaçava, no mesmo tom, o papel do intelectual como porta voz de valores universais e figura representativa da consciência de seu tempo, negando-lhe o lugar de condutor da luta popular: "o que os intelectuais descobriram recentemente é que as massas não necessitam deles para saber; elas sabem perfeitamente, claramente, muito melhor do que eles; e elas o dizem muito bem" (FOUCAULT, 1979a, p. 71). Nesse sentido, é bastante esclarecedor o modo como Deleuze sintetiza o ponto de coincidência entre ambos: 
Para nós, o intelectual teórico deixou de ser um sujeito, uma consciência representante ou representativa. Aqueles que agem e lutam deixaram de ser representados, seja por um partido ou por um sindicato que se arrogaria o direito de ser a consciência deles. Quem fala e age? Sempre uma multiplicidade, mesmo que seja na pessoa que fala ou age. Nós somos todos pequenos grupos. Não existe mais representação, só existe ação: ação de teoria, ação de prática em relações de revezamento ou em rede (Idem, p. 70).

É notável, no entanto, que ao longo do diálogo entre Deleuze e Foucault o personagem paradigmático da prática intelectual ao qual ambos pretendem se opor seja mencionado apenas uma única vez, e justamente por ocasião da primeira consideração de Foucault dirigida a Deleuze:

Um maoísta me dizia: "Eu compreendo porque Sartre está conosco, porque e em que sentido ele faz política; você, eu compreendo um pouco: você sempre colocou o problema da reclusão. Mas Deleuze, realmente eu não compreendo". Esta observação me surpreendeu muito porque isso me parece bastante claro (Idem, p. 69).

Iniciado o diálogo, Sartre permanecerá como uma espécie de pano de fundo exemplar da crítica, exemplo do tipo de atitude intelectual a ser ultrapassada no bojo de uma série de lutas que recusam o caráter identitário e universalista das formas tradicionalmente reconhecidas de resistência ao poder, mormente àquelas ligadas aos aparelhos partidários da esquerda comunista. E é no interior desta oposição entre práticas intelectuais diversas que Deleuze reconhecerá em Foucault uma das mais notáveis contribuições para uma luta política capaz de libertar os discursos historicamente censurados, proscritos, a fim de pô-los em circulação como forma de combate e resistência aos mecanismos constringentes do poder: "você foi o primeiro a nos ensinar - tanto em seus livros quanto no domínio da prática - algo de fundamental: a indignidade de falar pelos outros" (Idem, p. 72). Destarte, não é ao acaso que o próprio Foucault venha a considerar uma obra como Vigiar e punir como sendo apenas "uma pequena história, à margem, ao lado das lutas atuais" (FOUCAULT, 2001a, p. 1592), sugerindo que sua própria escrita filosófica devesse se apagar tão logo concluída sua instrumentalização política:

Escrever não me interessa a não ser na medida em que isso possa se incorporar à realidade de um combate, à título de instrumento, de tática, de esclarecimento. Gostaria que meus livros fossem uma espécie de bisturi, coquetéis Molotov ou minas, e que se carbonizassem depois do uso ao modo dos fogos de artifício (Idem, p. 1593).

No tocante à Jean-Paul Sartre, como sabemos, mesmo antes de seu "alinhamento" público junto ao Partido Comunista Francês (1952) - um alinhamento afirmado ao modo de quem pretende "declarar um acordo com os comunistas sobre assuntos precisos, pensando a partir dos meus princípios e não do deles" (SARTRE, 1975, p. 168) -, o filósofo já representara, na cena pública, a figura do intelectual universal, quer dizer, daquele que encarna a consciência moral e política de seu tempo, expressando a síntese de uma sociedade despedaçada porquanto interiorizou seu despedaçamento e suas contradições; um tipo intelectual no qual condensava-se a máxima tensão entre as formas legítimas da universalidade política - ainda por realizar-se - e a falsa universalidade representada pela burguesia, que dissimula ser a porta voz de valores emancipatórios para melhor naturalizar a sua dominação. Assim, por exemplo, nas célebres conferências realizadas por Sartre em setembro e outubro de 1965 em Tóquio e Quioto, intituladas "Em defesa dos intelectuais", o intelectual receberá a seguinte caracterização:

[o intelectual] é um subproduto de nossas sociedades e a contradição da verdade e da crença, do saber e da ideologia, do livre pensamento e do princípio de autoridade; não é o produto de uma práxis intencional, mas de uma reação interna, quer dizer, do relacionamento, na unidade sintética de uma pessoa, de estruturas incompatíveis entre si. Mas, olhando bem, suas contradições são as de cada um e da sociedade inteira. Todos têm os seus fins roubados, todos são meios de fins que lhes escapam e que são fundamentalmente inumanos, todos são divididos entre o pensamento objetivo e a ideologia. Simplesmente, essas contradições permanecem, em geral, no nível do vivido e se manifestam seja pela insatisfação de necessidades elementares, seja como um mal-estar (entre os assalariados das classes médias, por exemplo) cujas causas não se procuram. /.../ E cada um, mesmo que ignore, visa essa tomada de consciência que permitiria ao homem retomar o controle dessa sociedade selvagem que faz dele um monstro e 
um escravo. O intelectual, por sua própria contradição - que se torna sua função -, é levado a realizar para si mesmo e, em consequência, para todos, a tomada de consciência (SARTRE, 1994, p. 51-52).

Tratava-se em Sartre, portanto, da compreensão do intelectual como encarnação de vanguarda das contradições entre o universal e o particular no campo do saber técnico e da prática cotidiana: assimilável amiúde à figura do escritor engajado - uma espécie de protótipo exemplar da prática pública proporcionada pela livre atividade do espírito -, o intelectual sartriano faz da experiência da escrita o lugar de uma intervenção política que pretende "desvendar o mundo e especialmente o homem para os outros homens, a fim de que estes assumam em face do objeto, assim posto a nu, sua inteira responsabilidade" (SARTRE, 1999a, p. 21). Daí que Sartre venha a fazer de sua atividade intelectual, mormente em seus anos de aproximação com o marxismo, uma maneira de colocar-se ao lado "daqueles que pretendem mudar ao mesmo tempo a condição social do homem e a concepção que ele tem de si próprio” (SARTRE, 1999b, p. 121). Ou ainda, nas palavras de Herbert Marcuse: se a filosofia sartriana converte-se em política é porque, nela, "nenhum conceito filosófico pode ser pensado fora nem desenvolvido sem compreender dentro de si mesmo a inumanidade que é organizada hoje pelos governantes e aceita pelos governados” (MARCUSE, 1970, p. 93).

Dois estilos de intelectual engajado, duas formas de conceber a atividade prática e política do intelectual em meio as tormentas políticas de nosso tempo: ou bem a "escrita militante" de Foucault, para a qual não se tratava mais de fornecer o fio condutor do combate ou o aparelho teórico que viesse a unificar as lutas - como se fosse o caso de pronunciar-se na condição de "Filosofo" -, mas sim de entregar-se a um tipo de atuação setorial de constituição de estratégias possíveis em âmbitos locais; ou bem o modelo sartriano, "clássico", por assim dizer, do "intelectual total" e universal, para o qual a "política é essencialmente uma questão global, isto é, uma questão de Estado; [e] o poder é essencialmente o poder do Estado” (WOLFF, 2006, p. 63). Ora, cada uma destas atitudes e perfis intelectuais responde, em última instância, à tensão entre a realização política da universalidade e a reivindicação da particularidade - compreendida como esfera de resistência frente a uma racionalidade que pretende destinar a cada um sua identidade e localidade universais - no âmbito de uma luta de resistência contra o poder que possa igualmente denunciá-lo sob o aspecto do exercício constringente da técnica, do saber e da objetividade.

Nesse sentido, e dadas estas considerações preliminares, pretendemos, nas linhas que se seguem, opor sumariamente as trajetórias teóricas de Sartre e Foucault a fim de medir as distâncias e os deslocamentos produzidos por duas obras gestadas em correlação com os desafios de seu próprio tempo e com as exigências de formação de um campo político de resistência face às formas modernas de exercício do poder - seja na condição de reunir esforços para penetrar em uma realidade mais geral do sentido e do valor, como pretendera Sartre $^{1}$, seja, como quer Foucault, na condição de levar à cabo uma recusa da postura do filósofo como "legislador do saber", empenhando-se, ao contrário, em uma reflexão sobre o estatuto pratico da verdade e de seu papel político em nossas sociedades. ${ }^{2}$

II.

Se quisermos fazer uso de uma perspectiva de análise bastante difundida, e que possui o mérito, para o pequeno espaço de que aqui dispomos, de encurtar a ordem das explicações, digamos que Sartre representa uma geração marcada por um momento filosófico centrado sobre o problema da consciência e do espírito; momento no qual a reflexão sobre a prática se dirigirá para as características "subjetivas" da ação (a vontade, a escolha e a deliberação) a fim de considera-las em sua aderência ao real e em sua historicidade. Nesta medida, Merleau-Ponty tem boa dose de razão ao afirmar que as descrições fenomenológicas fornecidas por Sartre em $O$ ser e o nada possuem o inegável mérito de circunscrever, de maneira aguda e com nova 
profundidade, o "problema central da filosofia tal como ele se apresenta a nós depois das aquisições dos últimos séculos":

\begin{abstract}
Após Descartes, não se pode negar que a existência como consciência se distingue radicalmente da existência como coisa, e que a relação de uma a outra seja aquela do vazio ao pleno. Após o século XIX e tudo o que ele nos ensinou sobre a historicidade do espírito, não se pode negar que a consciência está sempre em situação. Cabe à nós compreender as duas coisas ao mesmo tempo (MERLEAU-PONTY, 1996, p. 90, grifo nosso).
\end{abstract}

Este horizonte de questões relativas às condições da existência humana e da historicidade do espírito em sua relação com as coisas concretas e a mundaneidade do mundo, vocalizado por uma série de doutrinas filosóficas que insistem na definição do "homem" como ser-no-mundo (segundo o jargão heideggeriano)33, reflete, no plano do debate político sobre a prática intelectual, a alternativa do homem de letras entre a atitude de encerrar-se em sua própria interioridade, defendendo-a das contingências históricas, ou então entregar-se efetivamente à luta (CALVINO, 2006, p. 51). Assim, a ambiência política do intelectual, por aqueles anos, poderia ser caracterizada pela oposição entre "sofrer a ferida da realidade exterior" ao modo contemplativo (evadindo-se do real por meio do inesgotável repertório das metáforas interiores) ou opor uma resistência ativa ao mundo (Idem), recusando a rendição incondicionada às formas determinadas do real e à dimensão inercial das coisas. Ora, nas palavras de Ítalo Calvino, um romance como A náusea, publicado por Sartre em 1938, constituiria já os protestos de seu autor contra o "mergulho no mar da objetividade indiferenciada" por meio da afirmação "da consciência, da escolha, da liberdade" (Idem, p. 52).

Se quisermos insistir no jogo de contrastes, digamos ainda, para manter o vocabulário de Calvino, que Foucault pertence a um momento em que a objetividade vem a "anegar o eu" (ou o próprio "autor") manifestando-se na crise do espírito revolucionário, ou seja, na perda de confiança na destinação revolucionária de uma filosofia ou de um saber que deveria realizar-se em uma prática emancipatória universalista. Em outros termos, pode-se dizer que o desgaste das esperanças revolucionárias representaria um momento histórico em que, nas palavras de Calvino, "falha, no homem, a confiança para direcionar [globalmente] o curso das coisas":

[e isso] não por ser ele o sobrevivente de uma derrota pungente, mas, antes, por ver que as coisas (a grande política dos dois sistemas de força contrapostos, o desenvolvimento da técnica e do domínio das forças naturais) prosseguem por conta própria, integram um conjunto tão complexo que o esforço mais heroico só pode ser aplicado à tentativa de ter uma ideia de como é, de compreendê-lo, de aceitá-lo (Idem, p. 53).

É certo que Calvino tece suas considerações do ponto de vista da crítica e da expressão literária e, portanto, sua grade de análise deve ser objeto de uso cuidadoso, além do fato de que a descrição acima, a propósito da aceitação do mundo, sugere uma passividade que está longe da atitude teórica e da prática foucaultianas. No entanto, a imagem tecida por ele, em termos de uma contraposição entre a "crença revolucionária" e uma "rendição à objetividade", aponta para um contraste esclarecedor a respeito de um deslocamento da experiência histórica que conduz à compreensão de que a "objetividade da razão constrange-nos num assédio tão letal quanto a objetividade do absurdo” (Idem, p. 54).

Assim, transladando o jogo de contrastes da descrição de Calvino para o campo de uma história do pensamento filosófico, estaríamos, com a geração de Foucault, diante de um momento centrado sobre o problema geral da estrutura, no interior do qual a reflexão sobre a ação se voltaria aos sistemas constringentes de nossa atividade prática, quer dizer, aos processos anônimos que caracterizam sua estrutura sistêmica e sistematizante, sua espessura social e suas formas historicamente objetivadoras. Daí o fato de que, para a geração contemporânea à Foucault, entre outras coisas, o novo modelo de sentido proposto pela linguística estrutural tenderá a se generalizar sob a forma de um sistema de diferenças cuja validade parecerá se estender 
para todas as dimensões do conhecimento e, em última instância, de toda existência humana. Deste modo, como assinalará Frédéric Worns, o problema da estrutura acabará por "abalar não apenas a compreensão da 'história' ou da 'dialética', mas sim o problema do ser ou da existência, que havia caracterizado todo um momento [anterior] do pensamento filosófico" (WORNS, 2009, p. 474). Quer dizer:

\begin{abstract}
Inspirando-se na linguística "estrutural" e no modo de ser que ela atribui a "língua", é preciso compreender que a objetividade própria das ciências do homem não é o de uma coisa, mas o de um sentido de alguma forma depositado em um sistema de signos, um sentido que não depende do sujeito e que, no entanto, permanece um fato de cultura ou de instituição (Idem, p. 473).
\end{abstract}

Assim, o apelo ao sentido, a este puro excesso que trabalha toda a ação humana, acabaria por abrir espaço ao jogo de um sistema de signos sem objeto nem intenção: o sujeito, o vivido e o sentido não definem mais um objeto do saber sobre o homem, mas sim a ocasião de sua dissolução, como assinalava já Lévi-Strauss em seu $O$ pensamento selvagem (obra cujo capítulo final, como se sabe, é inteiramente dedicado à análise crítica do tema da história em Sartre). ${ }^{4}$ Será necessário, portanto, buscar na linguagem e na reflexão formal as condições de uma interrogação que permitiria, nas palavras do Foucault de As palavras e as coisas, "pensar mais de perto esta desaparição do homem em sua relação com nossa preocupação com a linguagem” (1999, p. 397).

Do ponto de vista da prática política efetiva, e das posições do intelectual engajado, não se trata mais de uma defesa da "grande política" ou da emancipação do gênero humano - com suas fórmulas relativas às condições práticas de realização do devir humano, de reconciliação do homem com o homem e com seu destino histórico de liberdade -, mas da acuidade de um esforço prático junto às tarefas de transgressão das formas do discurso verdadeiro, de seus efeitos práticos sobre o real e, portanto, dos modos de assujeitamento que ele autoriza: a prática intelectual, se não pretende colocar em marcha a mesma "política da verdade" que caberia a ela denunciar, deve iniciar sua tarefa por meio da desmistificação das grandes narrativas da política e do humanismo, realizando a crítica ao dispositivo moderno de nossos saberes antropológicos e de sua tendência à recolher as marcas do discurso na referência a um "sujeito" cuja pretensa natureza é a de sujeito fundador. Está em jogo, aqui, o estatuto político dos saberes sobre o "homem" (em domínios tão distintos quanto os da psiquiatria, da medicina, da punição carcerária e da sexualidade) e as divisões normativas que lhe são correlatas.

III.

Quão longe estaríamos, portanto, do velho humanismo sartriano, para o qual o poder, sem fórmula definida, liga-se primeiramente ao ato da consciência de pôr-se no mundo como indeterminação e liberdade, vale dizer, como dado existencial de nosso ser-no-mundo? Ação de ponta a ponta - no mundo e sobre as coisas do mundo -, e simultaneamente recusa a confundir-se com o ser bruto em si ou com a vida interior de nosso psiquismo, a consciência ou "realidade humana", para Sartre, antes de ser definível pela libido ou pela vontade de poder, "é escolha de ser" (1997, p. 735).

Daí que o "intelectual universal" Sartre e o "intelectual específico" Foucault venham a se contrapor, publicamente, por ocasião da polêmica desencadeada pelo anúncio da "morte do homem" - positividade epistêmica fundante do ordenamento do saber ocidental na modernidade - ao longo das considerações finais de As palavras e as coisas, obra publicada em 1966. Sartre reagirá afirmando que uma obra como As palavras e as coisas, tendo por pretexto a realização de uma arqueologia das ciências humanas, possui por alvo principal, em verdade, o marxismo e, de maneira geral, a própria possibilidade de conferir inteligibilidade à ação histórica: 
O que Foucault nos apresenta é, como bem notou Kanters, uma geologia: a série de camadas sucessivas que formam nosso "solo". Cada uma destas camadas define as condições de possibilidade de um certo tipo de pensamento que triunfou durante um certo período. Mas Foucault não nos diz o que seria o mais interessante: à saber, como cada pensamento é construído a partir destas condições, nem como os homens passam de um pensamento a outro. Para tanto, lhe seria necessário fazer intervir a práxis, logo, a história, e é precisamente isso que Foucault recusa. /.../ Por detrás da história, bem compreendido, é o marxismo que é visado. Trata-se de construir uma nova ideologia, a última barreira que a burguesia poderia ainda erguer contra Marx. / ... / Na impossibilidade de ultrapassar Marx, pretende-se suprimi-lo. Dir-se-á, então, que a história é inapreensível enquanto tal, que toda teoria da história é, por definição, "doxologia”, para retomar as palavras de Foucault (1966, p. 87-88).

Foucault, por sua vez, responderá a Sartre fazendo referência à sua Crítica da razão dialética (1960), obra que constituiria, de sua perspectiva, o "magnífico e patético esforço de um homem do século XIX para pensar o século XX”:

Grosso modo, pode-se dizer o seguinte: o humanismo, a antropologia e o pensamento dialético estão ligados. Aquilo que ignora o homem é a razão analítica contemporânea, que vimos nascer com Russel e que aparecerá em Lévi-Strauss e nos linguistas. Esta razão analítica é incompatível com o humanismo, enquanto a dialética convoca acessoriamente o humanismo. Ela o convoca por razões diversas: porque ela é uma filosofia da história, porque ela é uma filosofia da prática humana, porque ela é uma filosofia da alienação e da reconciliação. /.../ Ela promete o homem ao homem e, nesta medida, é indissociável de uma moral humanista. Neste sentido, os grandes responsáveis pela moral do humanismo contemporâneo são, evidentemente, Hegel e Marx. Ora, parece-me que, escrevendo a Crítica da razão dialética, de algum modo Sartre colocou um ponto final, tornando a fechar o parêntese sobre todo este episódio da nossa cultura, que se inicia com Hegel. /.../ Nesse sentido, Sartre é o último dos hegelianos, e eu diria mesmo o último marxista (2001, p. 560-570).

O último dos hegelianos, o último marxista: afinal, não fôra Sartre aquele que afirmara, apenas seis anos antes da publicação de As palavras e as coisas - obra na qual Marx emergirá como uma figura epistêmica completamente integrada ao saber do século XIX -, que o "marxismo ainda é bastante jovem, quase na infância, mal começou a desenvolver-se"? (1960, p. 29). ${ }^{6}$

Ocorre que ao explorar os saberes que precederam o impasse no qual se extraviou o humanismo filosófico - pego na emboscada de um círculo vicioso que o faria oscilar entre os polos do constituinte e do constituído, do transcendental e do empírico, do cogito e do impensado -, Foucault colocara em xeque não apenas a figura abstrata e universal do "sujeito", mas igualmente sua encarnação particularizada nas três formas principais da cultura moderna e de suas esperanças de realização prática: 1. o sujeito-proletariado do marxismo; 2. o sujeito-consciência da fenomenologia e do existencialismo; 3. o sujeito-razão do cientificismo positivista (BRUNI, 2006, p. 34). Assim, o Foucault de As palavras e as coisas esperava encontrar-se em condições de nos prevenir a respeito da "rede cerrada que, apesar das aparências, religa os pensamentos de tipo positivista ou escatológico (o marxismo em primeiro lugar) com as reflexões inspiradas pela fenomenologia” (1999, p. 332). ${ }^{7}$ Do homem alienado em Marx ao implícito e ao inatual em Husserl, passando pela consciência intencional em Sartre - "consciência" que se constitui, paradoxalmente, em seu movimento de visada e resistência à inumanidade das coisas e às determinações do ser -, tratara-se, sempre, de um pensamento empenhado em "desalienar o homem reconciliando-se com sua própria essência” e seu devir inesgotáveis (Idem, 338). Bem ao contrário, caberia reconhecer - e seria essa a tarefa mais urgente de nosso tempo que as pretensões redentoras da razão, da experiência vivida ou da consciência desalienante não são senão a expressão do complexo de saber-poder que preside as formas modernas de nossa sujeição, de sorte que a chave do poder está em sua capacidade de objetivação, em seu empreendimento de constituição do indivíduo - "sujeito" ou "consciência" - como domínio oferecido e disposto à inspeção dos saberes e ao postulado normativo da existência de uma verdade (psicológica, científica, social, política) do homem.

Como sabemos, para Foucault as relações de poder não comportam um lugar de exterioridade e, portanto, não admitem nenhuma espécie de transcendência: já não será mais possível postular uma instância limítrofe 
da linguagem do poder, mas apenas uma multiplicidade de poderes e de resistências locais cujas frentes de luta não cessam de se deslocarem umas em relação às outras. ${ }^{8}$ De modo diverso, para o "escritor" e "militante" Sartre, entregue ao engajamento, a filosofia e a literatura aparecerão como instâncias exteriores ao poder, desde que se dê a elas o lugar de expressão de uma ontologia da liberdade cujo deságue esteja em uma prática política de uma escrita engajada. ${ }^{9}$

IV.

Talvez fosse o caso de reconhecer que estamos diante de experiências do pensamento e da prática intelectual irremediavelmente distintas, sem comunicação possível. Caberia insistir, então, na distância que separa as experiências intelectuais e políticas de Sartre e de Foucault (a despeito da relativa proximidade de suas respectivas gerações).

Sartre pertencera à geração da Segunda Grande Guerra, encarnara as esperanças e as ilusões dos anos seguintes à Libération; tornara-se, a um só tempo, um "companheiro de rota" dos comunistas, mas igualmente um de seus críticos mais contundentes. Seu rompimento com o partido ocorrerá na esteira dos acontecimentos que culminariam com a entrada dos tanques soviéticos em Budapeste, no ano 1956, mas também se deveu às idiossincrasias próprias à conciliação, em sua filosofia, da afirmação ontológica da liberdade individual com a realidade de uma ação coletiva cuja estrutura dirigista representava a permanente ameaça de esmagamento da individualidade pelo peso da dimensão inercial do partido. ${ }^{10}$

Foucault, de sua parte, pertencera a uma época na qual a crítica ao comunismo "oficial" e à centralização partidária já recolhera seus fruto ${ }^{11} \mathrm{e}$ demandava uma série de esforços para escapar ao dilema da esquerda naquele momento, premida entre a tarefa teórica de recolocar em questão o tema do poder - dirigindo-o "tanto contra o marxismo quanto contra as concepções burguesas" (DELEUZE, 1986, p. 32) - e a urgência da agenda real de lutas pontuais, locais, específicas inspiradas pelo Maio de 68 francês (lutas não passíveis de totalização por um saber que se pretendesse global e universalizante dos processos sociais em curso (Idem)). Daí que seu campo teórico e sua militância política venham a inscrever-se em uma compreensão da luta que privilegia as formas de resistência ao poder naquilo que concerne à sua eficácia estratégica de controle e vigilância sobre os corpos em espaços de reclusão correcional - o chamado poder disciplinar, que opera na dimensão ínfima de uma tecnologia política do corpo (FOUCAULT, 1975, p. 30).

Ainda assim, há algo que os reúne em suas militâncias políticas: se o momento histórico que envolve as gerações de Sartre e Foucault é aquele de uma época marcada pela alternância entre a retomada da destinação revolucionária de uma filosofia que deve realizar-se (em sentido marxista) e a reivindicação da particularidade como esfera de resistência face a uma racionalidade identitária e tecnicista, esta alternância, todavia, não impediu o encontro de ambos no campo da intervenção política e social efetiva. ${ }^{12}$ Ora, se Sartre e Foucault puderam se encontrar, lado a lado, no campo da ação política efetiva, isto se deveu, antes de tudo, a uma atitude política comum a ambos: por razões diversas, cada qual é avesso a uma prática política que se prolongue em legitimidade mistificadora de direito; em ambos vigora uma postura decididamente anti-institucional e, em consequência, uma atitude cética diante do poder. Nesse sentido, para Sartre todo fundamento da prática política e do poder constituído repousa sobre a livre práxis do agente (e estaríamos diante de um fundamento que não mais fundamenta), o que significa que o revolucionário, cuja ação é a que melhor expressa as premissas de uma "filosofia da liberdade", é precisamente aquele que "contesta os direitos da classe privilegiada e, ao mesmo tempo, destrói a ideia de direito em geral" (SARTRE, 1976, p. 218). Para Foucault, por seu turno, o próprio esgotamento da concepção jurídica do poder implica em analisar o poder não mais em termos de direito, mas, ao contrário, em considerar os sistemas de direito 
em termos de poder: tratar-se-ia, então, de atacar o poder "lá onde ele se exerce sob outro nome - aquele da justiça" (FOUCAULT, 2001b, p. 1063).

Sartre quer construir uma ação política fundada em liberdade - isto é: na prática efetiva do agente e na possibilidade de recuperá-la face à ameaça constante de reificação da existência pela institucionalidade politicamente organizada. ${ }^{13}$ Foucault jamais cederá a tentação de propor uma "filosofia política" alternativa às formas do poder instituído, preferindo buscar no "vazio jurídico" da soberania o lugar de resistência prática ao poder. De uma ou de outra forma, o lugar de autoridade do poder dissolve-se na recusa à institucionalização mistificadora da ação política, quer dizer, na recusa à sua dimensão inercial ou objetivante, e isso não em nome de um voluntarismo ingênuo e inconsequente, mas sim porque se trata de denunciar e opor resistências às formas da contra-finalidade (Sartre) ou aos dispositivos constringentes do poder (Foucault). E talvez se pudesse aplicar a ambos, mutatis mutandis, a avaliação que Paul Veyne reservara à pessoa e ao pensamento de Foucault:

não admitia nenhuma transcendência fundadora, e nem por isso fôra um niilista: nele, a perda de todo fundamento metafísico ou religioso jamais desencorajou a liberdade de possuir convicções, esperanças, indignações, revoltas (2010, p. 10)

\section{NOTAS}

1. "É preciso uma determinação moral da pessoa para tratar como fim as outras pessoas; assim, a passagem da pseudo-História para a História verdadeira está submetida a esta determinação a-histórica de todos para a realização da moral. A revolução histórica depende da conversão moral". C.f. SARTRE, 1983, p. 54.

2. "Enfim, a questão política não é o erro, a ilusão, a consciência alienada ou a ideologia; é a própria verdade" C.f. FOUCAULT, 1979b, p. 14.

3. "As doutrinas contemporâneas", observa Alphonse de Waelhens, "repetem de bom grado que homem se define (se é que a ideia de definição the seja aplicável) por seu ser-no-mundo". C.f. WAELHENS, 2002, p. v.

4. "Acreditamos que o objetivo último das ciências dos homens não é o de constituir o homem, mas sim o de dissolvê-lo". C.f. LÉVI-STRAUSS, 2006, p. 294.

5. "Cada sociedade tem seu regime de verdade, sua 'política geral' de verdade, isto é, os tipos de discurso que ela acolhe e faz funcionar como verdadeiros; os mecanismos e instâncias que permitem distinguir os enunciados verdadeiros dos falsos, a maneira como se sanciona uns e outros; as técnicas e os procedimentos que são valorizados para a obtenção da verdade; o estatuto daqueles que têm o encargo de dizer o que funciona como verdadeiro". C.f. FOCAULT, 1979b, p. 12.

6. Neste como em outros pontos, o contraste com o Foucault de As palavras e as coisas não poderia ser maior: "No nível profundo do saber ocidental, o marxismo não introduziu nenhum corte real; alojou-se sem dificuldade, como uma figura plena, tranquila, confortável e, reconheça-se, satisfatória por um tempo (o seu), no interior de uma disposição epistemológica que o acolheu favoravelmente (pois foi ela justamente que lhe deu lugar) e que ele não tinha, em troca, nem o propósito de perturbar nem sobretudo o poder de alterar, por pouco que fosse, pois que repousava inteiramente sobre ela. O marxismo está no pensamento do século XIX como peixe nágua: o que quer dizer que noutra parte qualquer deixa de respirar". C.f. FOUCAULT, 1999, p. 274.

7. Nesse sentido, a "aproximação recente [entre o marxismo e a fenomenologia, da qual Sartre seria um exemplo paradigmático, apesar de Foucault não citá-lo] não é da ordem da conciliação tardia: ao nível das configurações arqueológicas, eles eram necessários, uns como outros - e uns aos outros - desde a constituição do postulado antropológico, isto é, desde o momento em que o homem apareceu como duplo empírico-transcendental [que dizer, 
a um só tempo, como objeto para um saber da empiricidade e condição de possibilidade de todo conhecimento possível]". C.f. FOUCAULT, 1999, p 332.

8. Trata-se de admitir, nas palavras do Foucault de Vigiar e punir, que o "poder se exerce mais que se possui, que não é o 'privilégio' adquirido ou conservado da classe dominante, mas o efeito de conjunto de suas posições estratégicas - efeito manifestado e às vezes reconduzido pela posição dos que são dominados”. C.f. FOUCAULT, 1975, p. 31.

9. "Eis-nos levados pela mão até o momento em que é preciso abandonar a literatura da exis para inaugurar a da práxis”. C.f. SARTRE, 1999a, p. 175.

10. Assim, como dirá Sartre em “O fantasma de Stalin”, artigo que marca seu violento rompimento com o partido, para a ortodoxia stalinista "cada pessoa torna-se suspeita, aos olhos de todos e mesmo aos seus próprios olhos, pela única razão de que sua unidade impede a assimilação absoluta”. C.f. SARTRE, 1965, p. 229.

11. Rememorando o momento de seus primeiros trabalhos, em especial História da loucura (1961), Foucault se lembrará da ambiência da esquerda à época como sendo refratária ao problema relativo aos efeitos de poder veiculados por saberes como a medicina e a psiquiatria, e isso tanto por conta do sectarismo partidário quanto pelas preocupações do marxismo em se "fazer reconhecer pela instituição universitária e pelo establishment": "Aquilo que eu havia tentado fazer neste domínio [do estudo dos efeitos de poder veiculados pela psiquiatria e/ou pela dimensão política de um saber como a medicina] foi recebido com um grande silêncio por parte da esquerda intelectual francesa. E foi somente por volta de 68, apesar da tradição marxista e apesar do P.C., que todas estas questões adquiriram uma significação política com uma acuidade que eu não suspeitava e que mostrava quanto meus livros anteriores eram ainda tímidos e acanhados. Sem a abertura política realizada naqueles anos, sem dúvida eu não teria tido coragem para retomar o fio destes problemas e continuar minha pesquisa no domínio da penalidade, das prisões e das disciplinas". C.f. FOUCAULT, 1979b, p. 2-3.

12. Como é sabido, nos anos 70, Sartre e Foucault se (re)descobrirão na rua: "eles estão lá, lado a lado, um distribuindo os folhetos, o outro carregando a bandeirola com Claude Mauriac, Genet, Deleuze, Glucksmann, etc., na Goutte d’Or, denunciando um crime racista; eles estão lá, no hall do ministério da Justiça, para apoiar as reivindicações dos detentos revoltados... Eles se sucedem em conferências de imprensa, apesar da surdez das mídias de então, não para falar em lugar das vítimas, mas para que se possa, enfim, escutá-las.” C.f. COLOMBEL, 2000, pp. 50-51.

13. Nesse sentido, é significativo o fato de que já para o Sartre de O ser e o nada a classe oprimida só possa afirmar-se, enquanto sujeito coletivo (ou "nós-sujeito"), às expensas e em relação à classe opressora, quer dizer, transformando-a, por sua vez, em "eles-objeto", em um movimento de retificação intrínseco ao que se poderia chamar de "realidade de classe”. C.f. SARTRE, 1997, p. 521-522.

\section{REFERÊNCIAS}

CALVINO, I. 2006. “O mar da objetividade”. In: Assunto encerrado - Discursos sobre literatura e sociedade. Trad. de Roberta Barni. São Paulo: CIA das Letras.

COLOMBEL, J. 2000. “Sartre et Foucault”. In: Le magazine litterárie. Dossier Sartre, n. 384, février.

DELEUZE, G. 1986. Foucault. Collection “Critique”. Paris: Les Éditions de Minuit.

FOUCAULT, M. 1979a. “Os intelectuais e o poder”. In: MACHADO, R. (org.). Microfísica do poder. Rio de Janeiro: Edições Graal.

Edições Graal.

1979b. "Verdade e poder". In: MACHADO, R. (org.). Microfísica do poder. Rio de Janeiro: 
1999. Les mots et les choses. Collection Tel Gallimard. Paris: Gallimard.

.2001a. "Sur la sellette". In: Dits et écrits I. 1954-1975. Paris: Quarto Gallimard.

.2001b. "L'homme est-il mort?". In: Dits et écrits I. 1954-1975. Paris: Quarto Gallimard.

MERLEAU-PONTY, M. 1996. “La querelle de l'existentialisme”. In: Sens et non-sens. Paris: Gallimard.

SARTRE, J. P. 1960. Critique de la raison dialectique (précédé de Question de méthode). Bibliothèque des Idées. Paris: Gallimard.

. 1965. “Le fantôme de Staline”. In: Situations, VII. Paris: Gallimard.

. 1966. “Jean-Paul Sartre répond”. In: PINGAUD, Jean-Paul Sartre. L’arc, n. 30.

. 1975. “Les communistes et la paix”. In: Situations, VI. Paris: Gallimard.

. 1976. "Matérialisme et révolution". In: Situations III. Paris: Gallimard.

. 1983. Cahiers pour une morale. Bibliothèque de Philosophie. Paris: Gallimard.

. 1994. Em defesa dos intelectuais. Trad. Sérgio Goes de Paula. Apresentação de Francisco C. Weffort. São Paulo: Ed. Ática, 1994.

. 1997. O ser e o nada. Trad. de Paulo Perdigão. Petrópolis: Vozes.

. 1999a. Que é a literatura? Trad. de Carlos Felipe Moisés. São Paulo: Ed. Ática.

. 1999b. "Apresentação de 'Les temps modernes'. In: Revista Praga, estudos marxistas 8. Trad. Oto Araújo Vale. São Paulo: Ed. Hucitec.

LÉVI-STRAUSS, C. 1962. La pensée sauvage. Agora (collection dirigée par François Laurent). Paris: Plon.

VEYNE, P. 2010. Foucault, sa pensée, sa personne. Paris: Éditions Albin Michel.

WAELHENS, A. 2002. "Une philosophie de l'ambigüité". In: MERLEAU-PONTY, M. La structure du comportement. Paris: Quadrige/PUF.

WOLFF, F. 2006. “O dilema dos intelectuais." Trad. Paulo Neves. In: NOVAES, Adauto (Org.). O silêncio dos intelectuais. São Paulo: Cia da Letras.

WORMS, F. 2009. La philsophie en France au XIXe. siècle. Moments. Collection Folio Essais. Paris: Gallimard. 